Washington University School of Medicine

Digital Commons@Becker

Open Access Publications

2021

\title{
African Americans have differences in CSF soluble TREM2 and associated genetic variants
}

\author{
Suzanne E. Schindler \\ Washington University School of Medicine in St. Louis \\ Carlos Cruchaga \\ Washington University School of Medicine in St. Louis \\ Amulya Jospeh \\ Washington University School of Medicine in St. Louis \\ Lena McCue \\ Washington University School of Medicine in St. Louis \\ Fabiana H.G. Farias \\ Washington University School of Medicine in St. Louis
}

See next page for additional authors

Follow this and additional works at: https://digitalcommons.wustl.edu/open_access_pubs

Please let us know how this document benefits you.

\section{Recommended Citation}

Schindler, Suzanne E.; Cruchaga, Carlos; Jospeh, Amulya; McCue, Lena; Farias, Fabiana H.G.; Wilkins, Consuelo H.; Deming, Yuetiva; Henson, Rachel L.; Mikesell, Robert J.; Piccio, Laura; Llibre-Guerra, Jorge J.; Moulder, Krista L.; Fagan, Anne M.; Ances, Beau M.; Benzinger, Tammie L.S.; Xiong, Chengjie; Holtzman, David M.; and Morris, John C., "African Americans have differences in CSF soluble TREM2 and associated genetic variants." Neurology Genetics. 7, 2. e571 (2021).

https://digitalcommons.wustl.edu/open_access_pubs/10336

This Open Access Publication is brought to you for free and open access by Digital Commons@Becker. It has been accepted for inclusion in Open Access Publications by an authorized administrator of Digital Commons@Becker. For more information, please contact vanam@wustl.edu. 
Authors

Suzanne E. Schindler, Carlos Cruchaga, Amulya Jospeh, Lena McCue, Fabiana H.G. Farias, Consuelo H. Wilkins, Yuetiva Deming, Rachel L. Henson, Robert J. Mikesell, Laura Piccio, Jorge J. Llibre-Guerra, Krista L. Moulder, Anne M. Fagan, Beau M. Ances, Tammie L.S. Benzinger, Chengjie Xiong, David M. Holtzman, and John C. Morris 


\section{African Americans Have Differences in CSF Soluble TREM2 and Associated Genetic Variants}

Suzanne E. Schindler, MD, PhD, Carlos Cruchaga, PhD, Amulya Joseph, BA, Lena McCue, PhD, Fabiana H.G. Farias, PhD, Consuelo H. Wilkins, MD, MSci, Yuetiva Deming, PhD, Rachel L. Henson, MS, Robert J. Mikesell, BS, Laura Piccio, MD, PhD, Jorge J. Llibre-Guerra, MD, MSc, Krista L. Moulder, PhD, Anne M. Fagan, PhD, Beau M. Ances, MD, PhD, Tammie L.S. Benzinger, MD, PhD, Chengjie Xiong, PhD, David M. Holtzman, MD, and John C. Morris, MD, on behalf of the Alzheimer's Disease Neuroimaging Initiative

Neurol Genet 2021;7:e571. doi:10.1212/NXG.0000000000000571

\section{Abstract}

\section{Objective}

To evaluate for racial differences in triggering receptor expressed on myeloid cells 2 (TREM2), a key immune mediator in Alzheimer disease, the levels of CSF soluble TREM2 (sTREM2), and the frequency of associated genetic variants were compared in groups of individuals who self-reported their race as African American (AA) or non-Hispanic White (NHW).

\section{Methods}

Community-dwelling older research participants underwent measurement of CSF sTREM2 concentrations and genetic analyses.

\section{Results}

The primary cohort included 91 AAs and 868 NHWs. CSF sTREM2 levels were lower in the AA compared with the NHW group $(1,336 \pm 470$ vs $1,856 \pm 624 \mathrm{pg} / \mathrm{mL}, p<0.0001)$. AAs were more likely to carry TREM2 coding variants (15\% vs $3 \%, p<0.0001)$, which were associated with lower CSF sTREM2. AAs were less likely to carry the rs 1582763 minor allele (8\% vs 37\%, $p<0.0001)$, located near MS4A4A, which was associated with higher CSF sTREM2. These findings were replicated in an independent cohort of 23 AAs and 917 NHWs: CSF sTREM2 levels were lower in the AA group $(p=0.03)$, AAs were more likely to carry coding TREM2 variants $(22 \%$ vs $4 \%, p=0.002)$, and AAs were less likely to carry the rs 1582763 minor allele ( $16 \%$ vs $37 \%, p=0.003)$.

\section{Conclusions}

On average, AAs had lower CSF sTREM2 levels compared with NHWs, potentially because AAs are more likely to carry genetic variants associated with lower CSF sTREM2 levels. Importantly, CSF sTREM2 reflects TREM2-mediated microglial activity, a critical step in the immune response to amyloid plaques. These findings suggest that race may be associated with risk for genetic variants that influence Alzheimer disease-related inflammation.

\author{
Correspondence \\ Dr. Morris \\ jcmorris@wustl.edu
}

\section{Editorial}

Race and Alzheimer

Disease Biomarkers: A

Neglected Race

Page e574

From the Department of Neurology (S.E.S., A.J., R.L.H., R.J.M., L.P., J.J.L.-G., K.L.M., A.M.F., D.M.H., J.C.M.), Department of Psychiatry (C.C., F.H.G.F.), and Division of Biostatistics (L.M., C.X.), Washington University School of Medicine, St. Louis, MO; Office of Health Equity and Department of Medicine (C.H.W.), Division of Geriatrics, Vanderbilt University Medical Center, Nashville, TN; Department of Internal Medicine (C.H.W.), Meharry Medical College, Nashville, TN; Alzheimers Disease Research Center (Y.D.), University of Wisconsin School of Medicine and Public Health, Madison; Brain and Mind Centre (L.P.), University of Sydney, NSW, Australia; and Mallinckrodt Institute of Radiology (B.M.A., T.L.S.B.), Washington University School of Medicine, St. Louis, MO. 


\section{Glossary}

AA = African American; AD = Alzheimer disease; ADNI = Alzheimer's Disease Neuroimaging Initiative; ADRC = Alzheimer Disease Research Center; ANCOVA = analysis of covariance; CDR = Clinical Dementia Rating; NfL = neurofilament light chain; NHW = non-Hispanic White; PC1 = principal component $1 ; \mathbf{p}$ Tau = phosphorylated tau 181; $\mathbf{s T R E M 2}=$ soluble TREM2; TREM2 = triggering receptor expressed on myeloid cells 2; tTau = total tau.

Alzheimer disease $(\mathrm{AD})$ dementia affects people of all races and ethnicities. ${ }^{1}$ Recent studies have found that key proteins associated with $\mathrm{AD}$, including CSF total tau (tTau) and phosphorylated tau 181 (pTau), vary between groups of individuals by self-reported race. ${ }^{2-5}$ Importantly, race is a social identity and does not always segregate with genetic markers of ancestry. ${ }^{6}$ Associations with race are affected by numerous nongenetic influences, including factors that affect health such as socioeconomic status, ${ }^{7}$ education, ${ }^{8}$ and stress. ${ }^{9}$ However, when individuals are grouped by self-reported race, African Americans (AAs) and non-Hispanic Whites (NHWs) have different frequencies of some gene variants known to modify risk for $\mathrm{AD}$ dementia. ${ }^{10}$

In the brain, triggering receptor expressed on myeloid cells 2 (TREM2) is expressed by microglia and is a key mediator of the innate immune response to amyloid plaques. ${ }^{11,12}$ Multiple coding variants in the TREM 2 gene have been associated with increased $\mathrm{AD}$ risk ${ }^{13-15}$ and are hypothesized to impair TREM2 function. ${ }^{16}$ The p.R47H and p.R62H variants, which are associated with $\mathrm{AD}$ risk in individuals of European ancestry, ${ }^{13,14}$ are less frequent in AA. ${ }^{17}$ CSF soluble TREM2 (sTREM2) is a biomarker of TREM2-mediated microglial activity, ${ }^{18-20}$ and CSF sTREM2 concentrations have been associated with some variants in TREM $2^{21}$ and $M S 4 A 4 A,{ }^{22}$ a gene that is also associated with $\mathrm{AD}$ risk. ${ }^{22,23}$ It is unknown whether average CSF sTREM2 levels vary in individuals grouped by racial identity.

We evaluated whether CSF sTREM2 and genetic variants known to be associated with CSF sTREM2 levels vary between AA and NHW groups. CSF sTREM2 concentrations, the frequencies of TREM2 coding variants, and the frequencies of 2 single nucleotide polymorphisms in or near MS4A4A were compared in AA and NHW groups.

\section{Methods}

\section{Participants}

The primary cohort for this study was from the Knight Alzheimer Disease Research Center (ADRC), which includes one of the largest groups of $\mathrm{AA}$ in $\mathrm{AD}$ research with both $\mathrm{CSF}$ biomarker and genetic data. ${ }^{4}$ This cohort consists of community-dwelling older adults, including participants with and without cognitive impairment, enrolled in research studies of memory and aging at Washington University in St. Louis. The cohort was recruited for research participation only and was not clinic-based. Most participants lived in the greater St. Louis metropolitan area, which is approximately $18 \%$ AAs and $77 \%$ NHWs. ${ }^{4}$ Recruitment methods included word of mouth from individuals who were already participants, community presentations and other outreach efforts, and occasionally physician referral. Eligibility criteria included the absence of major medical conditions (e.g., metastatic cancer) that could interfere with longitudinal participation, but common chronic medical conditions (e.g., hypertension, diabetes, and depression) were permitted. The participants underwent annual clinical and cognitive assessments using the Uniform Data Set ${ }^{24}$ that includes the Clinical Dementia Rating $(\mathrm{CDR})^{25}$ and Mini-Mental State Examination. ${ }^{26}$ The CDR and etiologic diagnosis of the cause(s) of dementia when present was made by the clinician in accordance with standard criteria and methods ${ }^{24}$ without reference to the participant's performance on neuropsychological tests, the results of prior assessments, or biomarker results. Race, sex, and family history of $\mathrm{AD}$ were self-reported. Data were used for research purposes only.

After analyses of the Knight ADRC cohort were complete, an independent cohort was examined to determine whether the major findings could be replicated (racial differences in CSF sTREM2 and associated genetic variants). Data used for the replication cohort were obtained from the Alzheimer's Disease Neuroimaging Initiative (ADNI) database. The ADNI was launched in 2003 as a public-private partnership, led by Principal Investigator Michael W. Weiner, MD. For a full description of the ADNI cohort and protocols, see adni-info.org.

Participants in both the Knight ADRC and ADNI cohorts met the following criteria: (1) race was self-reported as either AA or NHW and (2) CSF sTREM2, A $\beta 42$, tTau, and pTau measurements were available within 1 year of a clinical assessment. No participants were represented in both cohorts.

\section{Standard Protocol Approvals, Registrations, and Patient Consents}

Written informed consent was obtained from all participants and their study partners. All procedures were approved by Washington University's Human Research Protection Office.

\section{Sequencing and Genotyping}

The APOE genotype was determined by genotyping rs 7412 and rs429358 using TaqMan genotyping technology. ${ }^{27}$ TREM2 variants were determined by pooled DNA sequencing. ${ }^{15}$ The rs 1582763 and rs6591561 polymorphisms associated with $M S 4 A 4 A$ were genotyped using Illumina arrays. ${ }^{15}$ 
Principal components were computed using genome-wide genotyping data. ${ }^{28}$ Estimates of African ancestry for each individual were established with the first principal component (PC1) which differentiates European and African ancestry. ${ }^{29}$ A higher PC1 value corresponds to greater African ancestry.

\section{CSF Collection and Analysis}

Methods for the Knight ADRC cohort are described here; for the ADNI cohort, the methods were similar and are described in detail online at adni-info.org. Lumbar puncture was performed as previously described. ${ }^{30}$ For CSF samples collected before October 11, 2016, A $\beta 42$, tTau, and pTau were measured with the corresponding Elecsys assays on a Roche Cobas e 601 analyzer. ${ }^{30}$ Elecsys data were not available for samples collected more recently (October 13, 2016, through February 12, 2019), but A $\beta 42$, tTau, and pTau were measured with the corresponding INNOTEST (Fujirebio) assays. Neurofilament light chain (NfL) was measured with an immunoassay kit manufactured by Uman Diagnostics. Concentrations of sTREM2 were measured with the same immunoassay in both the Knight ADRC and ADNI cohorts. ${ }^{22}$ To decrease plate-toplate variability due to potential matrix effects, sTREM2 values were normalized using high and low pooled controls and bridging samples. ${ }^{22}$

\section{Statistical Analysis}

For analyses involving CSF A $\beta 42, \mathrm{tTau}$, and pTau, only values obtained with Elecsys assays (87\% of samples) were used because it is unclear whether INNOTEST values are comparable to those measured by Elecsys. CSF biomarker concentrations were transformed with the natural logarithm for visualization, analysis, and covariate adjustment. Characteristics of AA and NHW groups were compared using Student $t$ tests for continuous variables and $\chi^{2}$ tests or Fisher exact tests for categorical variables. The significance of differences in CSF biomarker values between AA and NHW groups was calculated by Mann-Whitney tests for unadjusted raw values and Student $t$ tests for natural logarithm-transformed values. Comparisons of CSF biomarkers were performed with Student $t$ tests of the natural logarithm-transformed value unless otherwise specified. Spearman correlations were performed between natural logarithm-transformed CSF biomarker concentrations and PC1 because PC1 was not normally distributed.

Analysis of covariance (ANCOVA) models were implemented using natural logarithm-transformed CSF biomarker concentrations as the outcome variable. Predictors in the ANCOVA models were based on previously published models ${ }^{4}$ and included the following: race (AA or NHW), centered age (the age at CSF collection minus the mean age for the cohort [69.0 years]), sex, years of education (dichotomized as $\leq 12$ and $>12$ years of education), family history of dementia status (positive or negative, only available for the Knight ADRC cohort), APOE $\varepsilon 4$ status (carrier or noncarrier), dementia status $(\mathrm{CDR}=0$ or $\mathrm{CDR}>0)$, and every 2-way interaction among these variables. Genetic variant status (carrier or noncarrier) and the interaction of genetic variant status with all other covariates were entered into the CSF sTREM2 model to obtain covariate-adjusted $p$ values for each genetic variant. In the model incorporating both TREM2 coding variant status and rs1582763 minor allele (A) carrier status, the interaction between these variants was also included.

Statistical analyses were implemented using SAS 9.4 (SAS Institute Inc., Cary, NC). Plots were created with GraphPad Prism version 7.04 (GraphPad Software, La Jolla, CA). All $p$ values were from 2 -sided tests, and results were deemed statistically significant at $p<0.05$.

\section{Data Availability}

Data are available to qualified investigators on request to the Knight ADRC (knightadrc.wustl.edu/Research/ResourceRequest.htm) and ADNI (adni.loni.usc.edu/data-samples/accessdata/).

\section{Results}

\section{Participants}

The Knight ADRC cohort consisted of 959 participants who met the inclusion criteria: 91 AAs and 868 NHWs (table 1). The AA group was younger than the NHW group (66.1 \pm 8.2 vs $69.3 \pm 9.2$ years, $p=0.002$ ), less likely to have dementia ( $13 \%$ vs $25 \%, p=0.01$ ), less likely to have a family history of dementia ( $44 \%$ vs $56 \%, p=0.03$ ), and reported slightly fewer years of education $(15.2 \pm 2.9$ vs $15.9 \pm 2.7, p=0.02)$. The ADNI cohort consisted of 940 participants who met the inclusion criteria: 23 AAs and 917 NHWs (table 2). The AA group reported fewer years of education compared with the NHW group $(14.9 \pm 2.5$ vs $16.1 \pm 2.8, p=0.04)$, but did not differ significantly by age or dementia status.

\section{Differences in CSF Biomarkers by Self-Reported Race or Genetic Ancestry}

Concentrations of CSF biomarkers including sTREM2 were examined as a function of race. In the Knight ADRC cohort, there was no difference in CSF $A \beta 42$ concentrations (figure 1A) between AA and NHW groups. However, CSF tTau, pTau, NfL, and sTREM2 levels were lower in the AA compared with the NHW group $(p<0.0001$ for all) (figure $1, \mathrm{C}, \mathrm{E}$, $\mathrm{G}$, and I). CSF biomarker levels were also examined as a function of the PC1 measure of African genetic ancestry. PC1 was not correlated with CSF A $\beta 42$ (figure $1 \mathrm{~B}$ ), but was correlated with CSF tTau, pTau, NfL, and sTREM2 $(p<0.0001$ for all) (figure 1, D, F, H, and J), with lower levels of these biomarkers associated with higher African genetic ancestry. Even after adjusting for age, sex, years of education, family history of dementia, APOE $\varepsilon 4$ status, dementia status, and every 2 way interaction among these variables, there were highly significant reductions in CSF tTau, pTau, NfL, and sTREM2 in the AA compared with the NHW group $(p<$ 
Table 1 Characteristics of Individuals in the Knight Alzheimer Disease Research Center Cohort

\begin{tabular}{|c|c|c|c|c|c|}
\hline \multirow[b]{2}{*}{ Characteristic } & \multicolumn{2}{|c|}{ African American participants } & \multicolumn{2}{|c|}{ Non-Hispanic White participants } & \multirow[b]{2}{*}{$p$ Value } \\
\hline & $\mathbf{n}$ & & $\mathbf{n}$ & & \\
\hline Age at CSF collection, y & 91 & $66.1 \pm 8.2$ & 868 & $69.3 \pm 9.2$ & 0.002 \\
\hline Sex, n (\% female) & 91 & $50(55)$ & 868 & $473(55)$ & N.S. \\
\hline Years of education & 91 & $15.2 \pm 2.9$ & 868 & $15.9 \pm 2.7$ & 0.02 \\
\hline APOE \&4 status, $n$ ( $\%$ carrier) & 90 & $39(43)$ & 863 & $348(40)$ & N.S. \\
\hline CDR 0/0.5/1/2 $(\%>0)$ & 91 & $79 / 8 / 4 / 0(13)$ & 868 & 647/177/39/5 (25) & 0.01 \\
\hline MMSE (of 30) & 91 & $28.5 \pm 2.5$ & 868 & $28.3 \pm 2.5$ & N.S. \\
\hline Family history, $\mathrm{n}$ (\% positive) & 91 & $40(44)$ & 868 & $489(56)$ & 0.03 \\
\hline TREM2 variant carriers, $\mathrm{n}(\%)$ & 91 & $14(15)$ & 868 & $28(3)$ & $<0.0001$ \\
\hline rs1582763 genotype AA/AG/GG (minor allele [A] frequency) & 89 & $1 / 13 / 75(8)$ & 843 & 106/407/330 (37) & $<0.0001$ \\
\hline rs6591561 genotype GG/AG/AA (minor allele [G] frequency) & 88 & 9/31/48 (28) & 851 & 73/355/423 (29) & N.S. \\
\hline
\end{tabular}

Abbreviations: $C D R=$ Clinical Dementia Rating, where $C D R=0$ indicates cognitive normality and $C D R=0.5,1,2$, or 3 indicates very mild, mild, moderate, or severe dementia, repectively; MMSE = Mini-Mental State Examination, where a score of 30 is "best" and a score of 0 is "worst"; N.S. = not significant.

Continuous measures are presented as the mean \pm SD. The significance of differences between groups was determined by Student $t$ tests for continuous variables and by $\chi^{2}$ or Fisher exact tests for categorical variables. See figure 2 for a listing of specific TREM 2 variants by race.

$0.0001,<0.0001,0.0005$, and $<0.0001$, respectively, table 3 and tables e-1 to e-5, links.lww.com/NXG/A399). Race did not interact significantly with $A P O E \varepsilon 4$ in these models, but among APOE $\varepsilon 4$ carriers, pTau and tTau concentrations were lower in the AA compared with the NHW group $(p=0.0001$ and $p<0.0001$, respectively). In contrast, among APOE $\varepsilon 4$ noncarriers, there were no significant racial differences in pTau and tTau concentrations.

Because the AA and NHW groups in the Knight ADRC cohort had significant differences in some major covariates (age, years of education, presence of dementia, and family history of $\mathrm{AD})$, an alternative approach was performed to evaluate whether differences in CSF biomarker levels as a function of race were a result of inadequate statistical correction for covariates. A computer algorithm matched each AA participant, if possible, with $1 \mathrm{NHW}$ participant by closest age (within 3 years), years of education (within 2 years), presence of dementia $(\mathrm{CDR}=0$ or $\mathrm{CDR}>0)$, and family history of $\mathrm{AD}$. NHW matches were available for 86 of 91 AA participants (table e-6, links.lww.com/NXG/A399). In this subcohort where there were no significant differences between the AA

Table 2 Characteristics of Individuals in the Alzheimer's Disease Neuroimaging Initiative Cohort

\begin{tabular}{|c|c|c|c|c|c|}
\hline \multirow[b]{2}{*}{ Characteristic } & \multicolumn{2}{|c|}{ African American participants } & \multicolumn{2}{|c|}{ Non-Hispanic White participants } & \multirow[b]{2}{*}{$p$ Value } \\
\hline & $\mathbf{n}$ & & $\mathbf{n}$ & & \\
\hline Age at CSF collection, y & 23 & $73.8 \pm 7.4$ & 917 & $73.3 \pm 7.2$ & N.S. \\
\hline Sex, n (\% female) & 23 & $13(57)$ & 917 & $393(43)$ & N.S. \\
\hline Years of education & 23 & $14.9 \pm 2.5$ & 917 & $16.1 \pm 2.8$ & 0.04 \\
\hline APOE \&4 status, $n$ ( $\%$ carrier) & 23 & $11(48)$ & 917 & $441(48)$ & N.S. \\
\hline CDR 0/0.5/1 $(\%>0)$ & 23 & $9 / 11 / 3(61)$ & 917 & 265/551/101 (71) & N.S. \\
\hline TREM2 variant carriers, $\mathrm{n}(\%)$ & 23 & $5(22)$ & 917 & $35(4)$ & 0.002 \\
\hline rs1582763 genotype AA/AG/GG (minor allele [A] frequency) & 22 & 0/7/15 (16) & 913 & $130 / 424 / 359(37)$ & 0.003 \\
\hline rs6591561 genotype GG/AG/AA (minor allele [G] frequency) & 23 & 3/9/11 (33) & 917 & $83 / 402 / 432(31)$ & N.S. \\
\hline
\end{tabular}

Abbreviations: $C D R=$ Clinical Dementia Rating, where $C D R=0$ indicates cognitive normality and $C D R=0.5,1,2$, or 3 indicates very mild, mild, moderate, or severe dementia, respectively; N.S. = not significant.

Continuous measures are presented as the mean \pm SD. The significance of differences between groups was determined by Student $t$ tests for continuous variables and by $\chi^{2}$ or Fisher exact tests for categorical variables. See figure 2 for a listing of specific TREM 2 variants by race. 
A. $A \beta 42$ by race

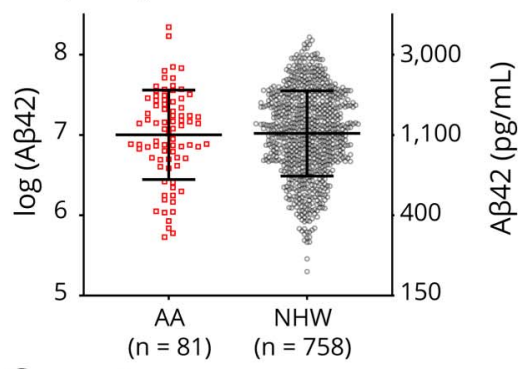

C. t-Tau by race

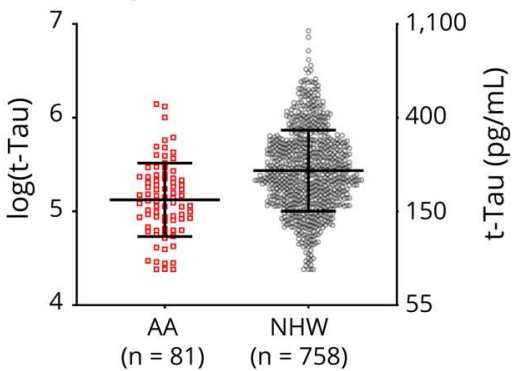

E. p-Tau by race

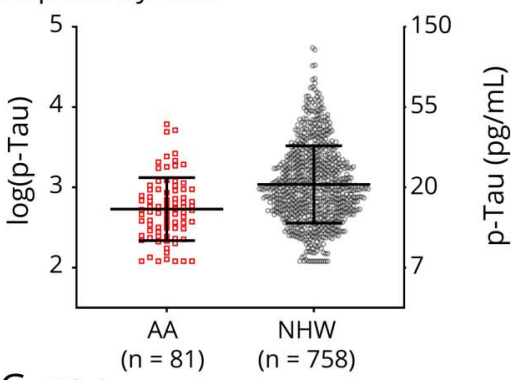

G. NfL by race

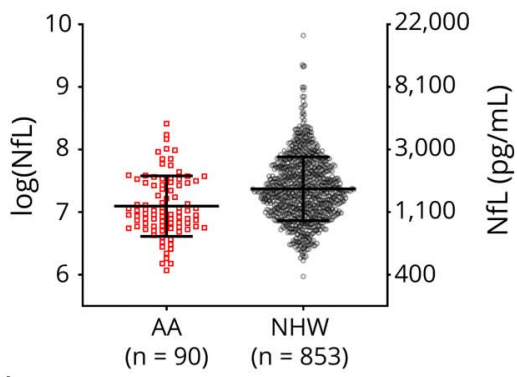

I. STREM2 by race

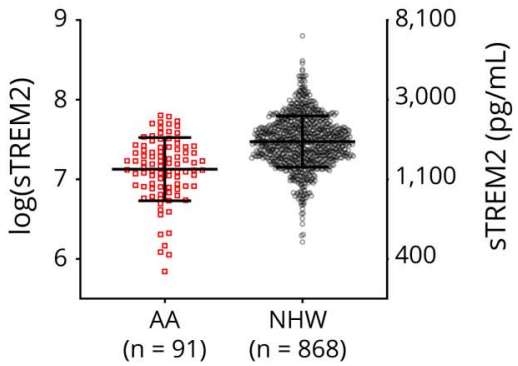

B. $A \beta 42$ vs genetic ancestry

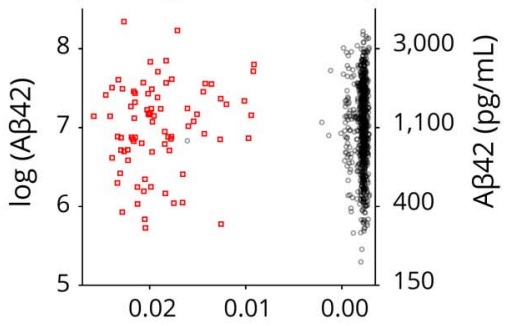

D. t-Tau vs genetic ancestry

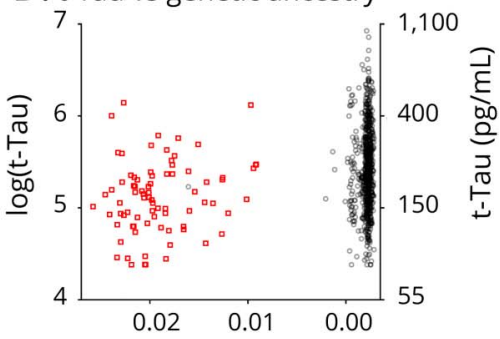

F. p-Tau vs genetic ancestry

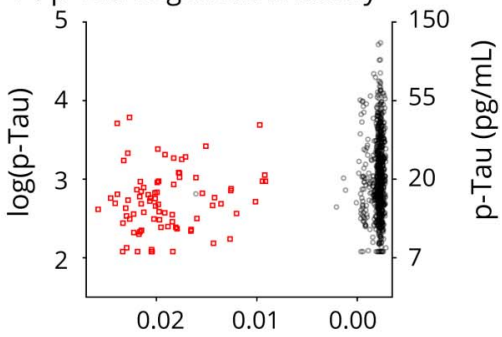

H. NfL vs genetic ancestry

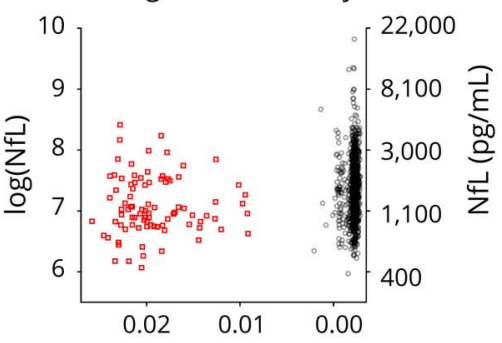

J. STREM2 vs genetic ancestry

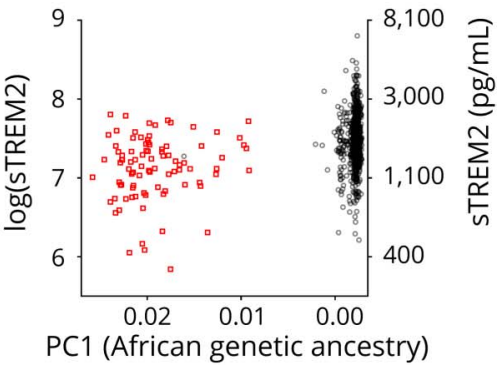

The natural logarithm of CSF concentrations of amyloid- $\beta 42$ (Aß42, A, B), total tau (tTau, C, D), phosphorylated tau 181 (pTau, E, F), neurofilament light chain (NfL, G, H), and soluble triggering receptor expressed on myeloid cells 2 (sTREM2, I, J) was plotted as a function of selfreported race (African American [AA] or nonHispanic White [NHW]) or a measure of African genetic ancestry (PC1, higher values correspond to higher African genetic ancestry, axis is reversed). Corresponding concentrations in $\mathrm{pg} / \mathrm{mL}$ are shown on the right axis. Red squares represent samples from AAs, and gray circles represent samples from NHWs. The number of individuals in each group is listed (n). and NHW groups by major covariates, the AA group had lower CSF tTau, pTau, and sTREM2 compared with the NHW group $(p<0.0001$ for all).
In the ADNI cohort, the power to detect racial differences in CSF biomarkers was much lower because of the smaller size of the AA group ( $n=23 \mathrm{AA}$ in the ADNI cohort vs $n=91 \mathrm{AA}$ in 
the Knight ADRC cohort). There were no significant racial differences in concentrations of CSF A $\beta 42$, tTau, pTau, or NfL, likely because the cohort was insufficiently powered to see these smaller effects. However, even with such a small AA group, CSF sTREM2 concentrations were significantly lower in the AA compared with the NHW group $(p=0.001)$, and PC1 was correlated with CSF sTREM2 $(p=0.0005)$ (table 4$)$. After adjusting for covariates, the racial difference in CSF sTREM2 remained significant $(p=0.03)$. In the ADNI cohort, the AA and NHW groups were relatively well matched for covariates, so no matching secondary analysis was performed.

\section{Concordance of Self-Reported Race and Genetic Ancestry}

Genetic ancestry data were available for 937 of 959 individuals (98\%) in the Knight ADRC cohort and all individuals in the ADNI cohort. In both cohorts, only 1 individual was discordant; in both cases, the individual identified as NHW but had a PC1 consistent with high African genetic ancestry. Because selfreported race and genetic ancestry were almost completely concordant in these 2 cohorts (99.9\%), analyses using either measure resulted in nearly identical findings. Self-reported race was used as the primary categorical measure of race because race is a social rather than a genetic categorization. In addition, most individuals (patients and potential research participants) cannot provide a quantitative measure of their genetic ancestry (e.g., PC1), but they can report their racial identity. Most clinical trials for $\mathrm{AD}$ recruit racial and ethnic groups based on self-reported race, not on GWAS data. Therefore, self-reported race is more broadly relevant to individuals and to other research studies.

\section{Differences in TREM2 Coding Variants and MS4A4A Polymorphisms by Self-Reported Race} The frequency of TREM2 coding variant status (any coding variant vs wild-type sequence) in the AA and the NHW groups was compared. AAs were more likely than NHWs to carry a TREM 2 coding variant in both the Knight ADRC cohort (15\% vs $3 \%, p<0.0001)$ and the ADNI cohort ( $22 \%$ vs $4 \%, p=0.002)$. This difference was primarily driven by a higher frequency of the p.T96K, p.L211P, and p.W191X variants in the AA group; these variants were in linkage disequilibrium.

The frequencies of 2 polymorphisms in the MS4A4A gene region that have been associated with CSF sTREM2 concentrations were evaluated. The minor allele $(\mathrm{A})$ of rs1582763, an intergenic variant located near MS4A4A, was less frequent in the AA than the NHW group in both the Knight ADRC cohort (minor allele frequency $8 \%$ vs $37 \%, p<0.0001$ ) and the ADNI cohort ( $16 \%$ vs $37 \%, p=0.003)$. In contrast, the frequency of the rs6591561 minor allele (G) in $M S 4 A 4 A$ was not significantly different in the AA and NHW groups in the Knight ADRC cohort (28\% vs $29 \%$ ) or the ADNI cohort ( $33 \%$ vs $31 \%$ ).

\section{Effects of Coding TREM2 Variants and rs1582763 on CSF STREM2 Concentrations}

As detailed above, AAs were more likely to carry a TREM2 coding variant and less likely to carry the rs 1582763 minor allele (A). We examined how these genetic factors affected concentrations of CSF sTREM2 in the better-powered Knight ADRC cohort. Individuals carrying a TREM2 coding variant had lower CSF sTREM2 concentrations (figure 2A) ( $p<0.0001$ before and $p=0.02$ after covariate adjustment), and individuals carrying the minor allele (A) of rs 1582763 had higher sTREM 2 concentrations (figure 2B) $(p<0.0001$ before and after covariate adjustment).

We hypothesized that the difference between AA and NHW groups in CSF sTREM2 concentrations was largely explained by the different frequencies of TREM2 coding variants and rs1582763 (A). The effects of carrying a TREM2 coding variant and/or rs 1582763 (A) were additive such that TREM2 coding variant carriers and rs 1582763 (A) noncarriers had the lowest CSF sTREM2 levels (figure 2C). In the Knight ADRC cohort, a model for CSF sTREM2 was implemented that included race, TREM2 coding variant carrier status, rs1582763 (A) carrier status, and all covariates and interactions. After accounting for these 2 genetic factors and covariates, concentrations of CSF sTREM2 were not significantly different in AA and NHW groups (table e-7, links.lww.com/ $\mathrm{NXG} / \mathrm{A} 399)$, implying that racial differences in the frequencies of coding TREM2 variants and rs1582763 (A) were a major driver of racial differences in CSF sTREM2 levels. Similar trends were seen in the ADNI cohort (figure e-1), although the small size of the AA cohort did not provide adequate power for a complex analysis. In summary, the lower average concentrations of CSF sTREM 2 in AA may be related to the higher frequency of coding TREM2 variants and the lower frequency of the rs1582763 minor allele (A).

\section{Discussion}

In the Knight ADRC cohort, which includes one of the largest groups of $\mathrm{AA}$ in $\mathrm{AD}$ research with both CSF biomarker and genetic data, we found that the AA group had lower average CSF sTREM2 levels compared with the NHW group. Our analyses suggested that the lower CSF sTREM2 levels in AA could be related to differences in genetic variant frequencies between AA and NHW groups: AAs had a higher frequency of TREM2 coding variants, which were associated with lower CSF sTREM2; and AAs had a lower frequency of rs 1582763 (A), which was associated with higher CSF sTREM2. After these differences were found in the Knight ADRC cohort, the ADNI cohort was evaluated specifically to determine whether these differences could be replicated, reducing the possibility of false discovery. Although the sizes of the AA groups in both cohorts were relatively small, the findings in both the Knight ADRC and ADNI cohorts were similar and highly statistically significant. Identification of differences in even small cohorts is important, as it may justify larger and more comprehensive studies.

The differences we reported were between racial groups, but there are likely numerous individual-level factors that modify 
Table 3 CSF Biomarker Values of Individuals in the Knight Alzheimer Disease Research Center Cohort

\begin{tabular}{|c|c|c|c|c|c|}
\hline \multirow[b]{2}{*}{ Characteristic } & \multicolumn{2}{|c|}{ AA participants } & \multicolumn{2}{|c|}{ NHW participants } & \multirow[b]{2}{*}{$p$ Value } \\
\hline & $\mathbf{n}$ & & $\mathbf{n}$ & & \\
\hline \multicolumn{6}{|c|}{ Unadjusted raw concentrations $( \pm S D)$} \\
\hline Elecsys $\mathrm{A} \beta 42, \mathrm{pg} / \mathrm{mL}$ & 81 & $1,271 \pm 703$ & 758 & $1,277 \pm 647$ & N.S. \\
\hline Elecsys tTau, pg/mL & 81 & $182 \pm 77$ & 758 & $253 \pm 120$ & $<0.0001$ \\
\hline Elecsys pTau, pg/mL & 81 & $16.6 \pm 7.3$ & 758 & $23.6 \pm 13.4$ & $<0.0001$ \\
\hline INNOTEST Aß42, pg/mL & 10 & $893 \pm 315$ & 110 & $927 \pm 340$ & N.S. \\
\hline INNOTEST tTau, pg/mL & 10 & $253 \pm 123$ & 110 & $411 \pm 248$ & 0.02 \\
\hline INNOTEST pTau, pg/mL & 10 & $46.2 \pm 18.2$ & 110 & $66.5 \pm 32.1$ & 0.02 \\
\hline $\mathrm{NfL}, \mathrm{pg} / \mathrm{mL}$ & 90 & $1,363 \pm 755$ & 853 & $1,837 \pm 1,281$ & $<0.0001$ \\
\hline sTREM2, pg/mL & 91 & $1,336 \pm 470$ & 868 & $1,856 \pm 624$ & $<0.0001$ \\
\hline \multicolumn{6}{|c|}{ Unadjusted natural logarithm-transformed values ( \pm SD) } \\
\hline Elecsys $A \beta 42$ & 81 & $7.00 \pm 0.56$ & 758 & $7.02 \pm 0.53$ & N.S. \\
\hline Elecsys tTau & 81 & $5.12 \pm 0.39$ & 758 & $5.44 \pm 0.43$ & $<0.0001$ \\
\hline Elecsys pTau & 81 & $2.73 \pm 0.39$ & 758 & $3.04 \pm 0.48$ & $<0.0001$ \\
\hline NfL & 90 & $7.10 \pm 0.48$ & 853 & $7.37 \pm 0.51$ & $<0.0001$ \\
\hline STREM2 & 91 & $7.13 \pm 0.40$ & 868 & $7.47 \pm 0.32$ & $<0.0001$ \\
\hline \multicolumn{6}{|c|}{ Covariate-adjusted natural logarithm-transformed values $( \pm$ SE) } \\
\hline Elecsys $A \beta 42$ & 81 & $6.79 \pm 0.08$ & 758 & $6.92 \pm 0.03$ & 0.10 \\
\hline Elecsys tTau & 81 & $5.28 \pm 0.07$ & 758 & $5.53 \pm 0.03$ & $<0.0001$ \\
\hline Elecsys pTau & 81 & $2.87 \pm 0.08$ & 758 & $3.12 \pm 0.04$ & $<0.0001$ \\
\hline $\mathrm{NfL}$ & 90 & $7.21 \pm 0.08$ & 853 & $7.44 \pm 0.03$ & 0.0005 \\
\hline STREM2 & 91 & $7.38 \pm 0.07$ & 868 & $7.66 \pm 0.03$ & $<0.0001$ \\
\hline
\end{tabular}

Abbreviations: $\mathrm{AA}=$ African American; $\mathrm{A} \beta 42=$ amyloid- $\beta$ 42; NfL = neurofilament light chain; $\mathrm{NHW}=$ non-Hispanic White; N.S. = not significant; $\mathrm{pTau}=$ phosphorylated tau181; sTREM2 = soluble triggering receptor expressed on myeloid cells 2; tTau = total tau.

CSF biomarker values were transformed with the natural logarithm. The significance of differences in CSF biomarker values between AA and NHW participants was calculated by Mann-Whitney tests for unadjusted raw values and Student $t$ tests for unadjusted natural logarithm-transformed values. For each CSF biomarker, the natural logarithm-transformed value was the outcome variable in an analysis of covariance model with the following predictor variables: race (AA or NHW), centered age (the age at CSF collection minus the mean age for the cohort [69.0 years]), sex, years of education ( $\leq 12$ and $>12$ years of education), family history of dementia (positive or negative), $A P O E \& 4$ status ( $\varepsilon 4$ carrier or noncarrier), dementia status (CDR $=0$ or CDR $>0$ ), and every 2-way interaction among these variables. The estimated natural logarithm-transformed biomarker value for each race, adjusted for covariates, and the significance of race as a predictor variable ( $p$ value) in the model is shown.

CSF sTREM2 levels. Significant and reproducible differences in the frequencies of genetic variants between $\mathrm{AA}$ and $\mathrm{NHW}$ groups are unlikely to be explained by nonbiological factors, but the effects of these genetic differences on CSF sTREM2 concentrations could be susceptible to many nonbiological influences. Reasons for racial differences may include differences in social, geopolitical, and environmental factors, some of which may be related to systemic racism. These include disparities in socioeconomic status, ${ }^{7}$ education, ${ }^{8}$ and stress. ${ }^{9}$ Differences in medical comorbidities and physiology, such as the prevalence of cerebrovascular disease, ${ }^{1}$ may also contribute. Notably, some of these conditions may affect risk for $\mathrm{AD}$ dementia. ${ }^{1}$ The effects of these factors on CSF sTREM2 are unknown. Neither the Knight ADRC nor the ADNI data set currently includes detailed information about social determinants of health such as economic stability, access to healthy foods, neighborhood safety, and quality of education. Studies are needed that include much larger numbers of AA with detailed sociocultural and environmental data. ${ }^{31}$

The role of TREM2 in $\mathrm{AD}$ has been an active area of investigation because TREM2 variants were found to be associated with the risk of symptomatic $\mathrm{AD} \cdot{ }^{13,14}$ TREM2 is a microglial receptor that binds amyloid with high affinity and may mediate the inflammatory response to amyloid plaques. ${ }^{11,12}$ Higher TREM2 levels may ameliorate the effects of $\mathrm{AD}$ pathology, ${ }^{32}$ potentially by decreasing neuritic dystrophy ${ }^{33,34}$ and limiting spreading of pathologic tau seeds. ${ }^{35}$ CSF sTREM2 concentrations are not linearly associated with $\mathrm{AD}$ brain pathology, but are thought to peak 
Table 4 CSF Biomarker Values of Individuals in the Alzheimer's Disease Neuroimaging Initiative Cohort

\begin{tabular}{|c|c|c|c|c|c|}
\hline \multirow[b]{2}{*}{ Characteristic } & \multicolumn{2}{|c|}{ AA participants } & \multicolumn{2}{|c|}{ NHW participants } & \multirow[b]{2}{*}{$p$ Value } \\
\hline & $\mathbf{n}$ & & $\mathbf{n}$ & & \\
\hline \multicolumn{6}{|l|}{ Unadjusted raw values $( \pm S D)$} \\
\hline Elecsys CSF $A \beta 42, p g / m L$ & 23 & $1,179 \pm 601$ & 916 & $1,049 \pm 592$ & N.S. \\
\hline Elecsys CSF tTau, pg/mL & 23 & $283 \pm 141$ & 914 & $292 \pm 126$ & N.S. \\
\hline Elecsys CSF pTau, pg/mL & 23 & $28.1 \pm 16.1$ & 914 & $28.1 \pm 14.1$ & N.S. \\
\hline CSF NfL, pg/mL & 8 & $1,050 \pm 558$ & 292 & $1,499 \pm 943$ & 0.09 \\
\hline CSF STREM2, pg/mL & 23 & $3,007 \pm 1,541$ & 917 & $4,128 \pm 1,876$ & 0.001 \\
\hline \multicolumn{6}{|c|}{ Unadjusted natural logarithm-transformed values $( \pm S D)$} \\
\hline Elecsys CSF A 442 & 23 & $6.92 \pm 0.6$ & 916 & $6.81 \pm 0.5$ & N.S. \\
\hline Elecsys CSF tTau & 23 & $5.56 \pm 0.4$ & 914 & $5.59 \pm 0.4$ & N.S. \\
\hline Elecsys CSF pTau & 23 & $3.22 \pm 0.5$ & 914 & $3.22 \pm 0.5$ & N.S. \\
\hline CSF NfL & 8 & $6.89 \pm 0.4$ & 292 & $7.18 \pm 0.4$ & 0.07 \\
\hline CSF STREM2 & 23 & $7.91 \pm 0.4$ & 917 & $8.22 \pm 0.5$ & 0.001 \\
\hline \multicolumn{6}{|c|}{ Covariate-adjusted natural logarithm-transformed values $( \pm \mathrm{SE})$} \\
\hline CSF STREM2 & 23 & $7.87 \pm 0.15$ & 917 & $8.21 \pm 0.03$ & 0.03 \\
\hline \multicolumn{6}{|c|}{ 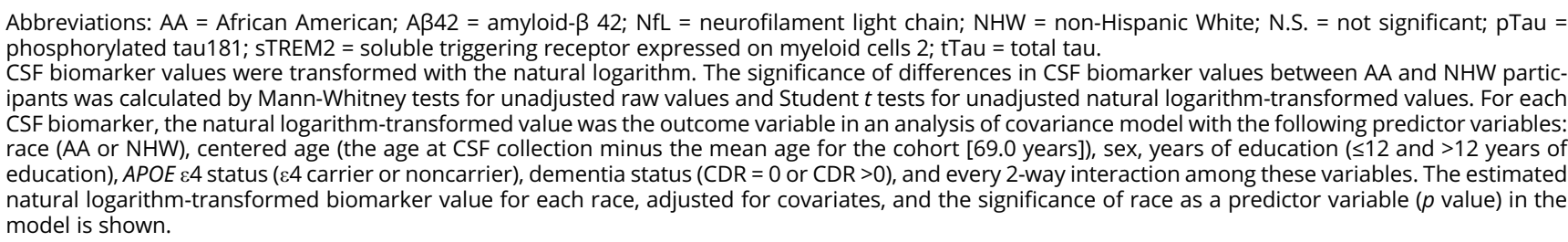 } \\
\hline
\end{tabular}

shortly after $\mathrm{AD}$ symptom onset and then plateau or decrease. ${ }^{36}$ In our mostly cognitively normal cohort, we found overall lower concentrations of CSF STREM2 in individuals carrying coding variants in TREM2, but these concentrations may later rise in response to $\mathrm{AD}$ pathology. One recent study (that did not account for race) demonstrated that lower baseline CSF sTREM2 is associated with faster cognitive decline in participants with symptomatic $\mathrm{AD} 20$; given our finding of lower average CSF sTREM2 in AA, this suggests that $\mathrm{AA}$ with $\mathrm{AD}$ may decline more rapidly.

TREM2 is a therapeutic target for $\mathrm{AD}$, and an anti-TREM2 antibody is being tested in an $\mathrm{AD}$ clinical trial. ${ }^{37}$ TREM2 may also influence antiamyloid treatments for $\mathrm{AD}-1$ study found that genetic deletion of TREM2 reduced antiamyloid monoclonal antibody-mediated clearance of amyloid plaques in cell culture experiments. ${ }^{38}$ Given the findings of this study that AAs have lower average CSF sTREM2, this prompts the hypothesis that poor clearance of amyloid plaques by antiamyloid monoclonal antibodies may be more common in AA. If true, this difference may not readily be discerned because AAs are severely underrepresented $(<3 \%)$ in many recent drug trials for $\mathrm{AD}^{39,40}$ In addition, because TREM2 is expressed not only in the brain, but also throughout the body in multiple myeloid cells, ${ }^{41}$ studies are needed to examine whether racial differences in the frequencies of TREM2 coding variants and rs 1582763 (A) translate to racial differences in other inflammatory conditions.

Some studies have found that $\mathrm{AAs}$ are at higher risk for $\mathrm{AD}$ dementia, ${ }^{42,43}$ although this is unclear, and the relationship between race and $\mathrm{AD}$ is likely very complex. ${ }^{44}$ Previous work has suggested that significant differences in $\mathrm{AD}$ pathophysiology exist between AA and NHW groups. ${ }^{2-5}$ In addition to our findings related to TREM2, we confirmed previous findings using more precise automated immunoassays that AAs had lower average CSF tTau and $\mathrm{pTau}^{2,4}$ We additionally found lower average NfL in AA compared with NHW groups. CSF NfL is a nonspecific marker of neuroxonal damage, and like tTau and pTau, NfL is typically elevated in $\mathrm{AD} .{ }^{45}$ The lower average levels of CSF tTau, $\mathrm{pTau}$, and NfL in the AA compared with the NHW group, even when average CSF A $\beta 42$ levels were not different between the groups, could indicate that AAs are less likely to develop neuronal damage in response to brain amyloid. It is unclear how these racial differences in CSF biomarkers relate to risk for $\mathrm{AD}$ dementia.

A major limitation of most $\mathrm{AD}$ studies is the underrepresentation of racial and ethnic minorities. Our study 


\section{A. STREM2 by TREM2 coding variant}

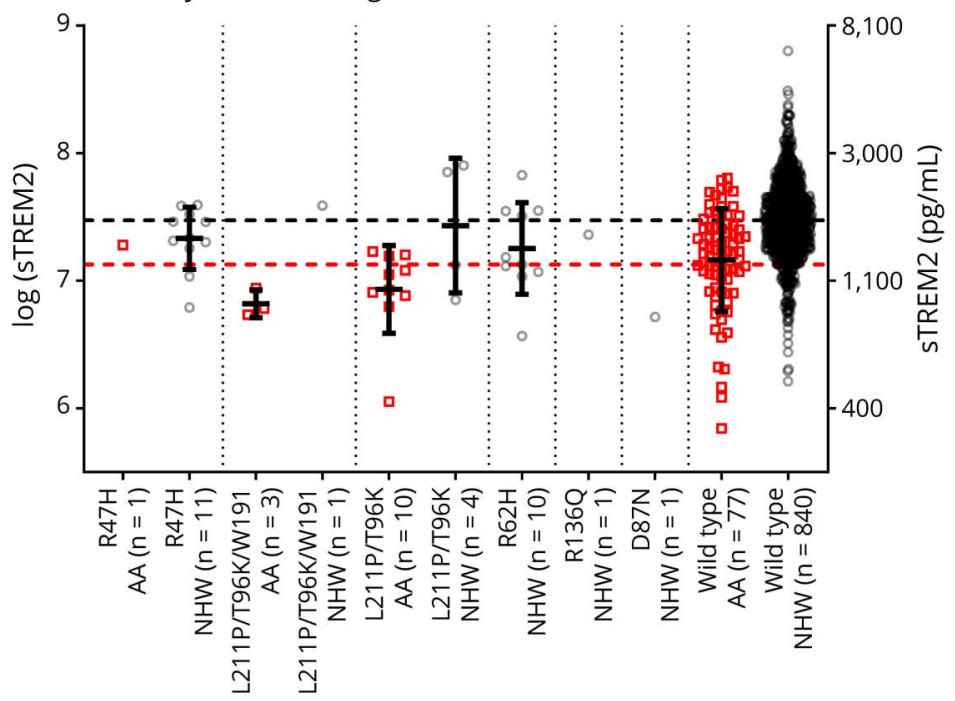

B. sTREM2 by rs1582763 genotype

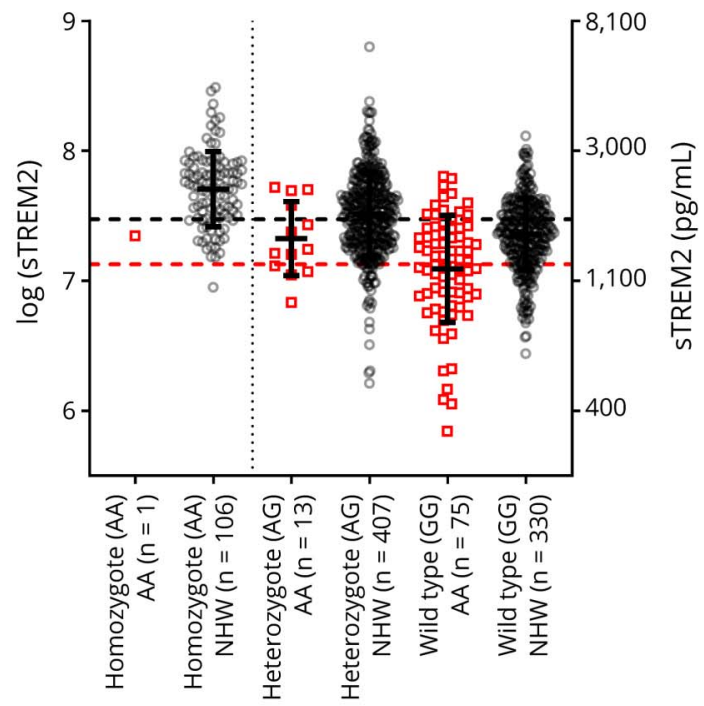

C. sTREM2 by TREM2 coding variant status and rs 1582763 (A) carrier status

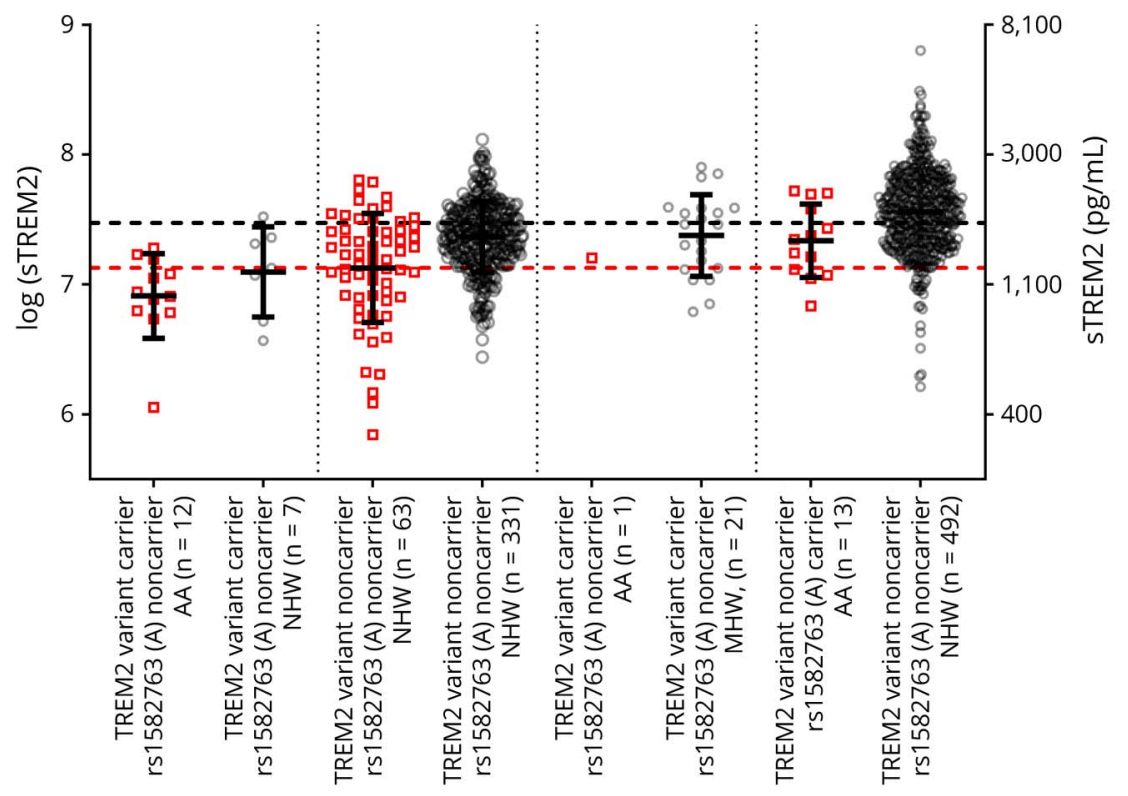

The natural logarithm of CSF concentrations of soluble triggering receptor expressed on myeloid cells 2 (STREM2) was plotted as a function of TREM2 coding variant (A), MS4A4A rs1582763 genotype (B), or TREM2 coding variant status and MS4A4A rs1582763 (A) carrier status (C). For all plots, the corresponding STREM2 concentrations in $\mathrm{pg} / \mathrm{mL}$ are shown on the right axis. Red squares represent samples from African Americans (AAs), and gray circles represent samples from non-Hispanic Whites (NHWs). Horizontal dashed lines indicate the mean sTREM2 levels for AA (red) and NHW (gray) groups. Vertical dotted lines separate genetic groups. The number of individuals in each group is listed (n).

used the Knight ADRC cohort, which includes one of the largest groups of $\mathrm{AAs}$ in $\mathrm{AD}$ research with both CSF biomarker and genetic data, but AAs were still underrepresented. Adequate representation of racial minorities in research studies is a challenge nationally due in part to historical abuses by researchers resulting in the mistrust of medical research by racial minority communities. ${ }^{46}$ Furthermore, deeply flawed and malignant suppositions about genetic differences between races have been used to oppress minority groups, especially $\mathrm{AA}^{47}$ Race can be an uncomfortable topic for some researchers and clinicians to discuss and study. However, it is imperative to study racial differences, including racial differences related to genetics, because they may influence $\mathrm{AD}$ pathophysiology, diagnosis, treatment efficacy, and outcomes. For example, applying cutoffs formulated with data from NHW cohorts could increase the frequency of $\mathrm{AD}$ misdiagnosis in AA patients. ${ }^{5}$ Even more concerning, AD clinical trials with inadequate representation of AA may lead to development of $A D$ therapies that are less likely to be safe or effective in AA as has occurred in other conditions such as 
hypertension. ${ }^{48}$ Development of $\mathrm{AD}$ therapies that are less likely to be effective in AA would further compound longstanding injustices experienced by AA. This study underscores the importance of carefully evaluating the effects of race on $\mathrm{AD}$ pathophysiology.

\section{Acknowledgment}

The authors express their gratitude to the research volunteers who participated in the studies from which these data were obtained and their supportive families. They thank the Clinical, Fluid Biomarker and Imaging Cores at the Knight ADRC for sample and data collection. They also thank Dr. Brian A. Gordon at Washington University for helpful discussions.

\section{Study Funding}

This study was supported by National Institute on Aging grants R03AG050921 and K23AG053426 (S.E. Schindler), T32AG000213 (Y. Deming), RF1AG058501 (C. Cruchaga and L. Piccio), R01AG054567 (T.L.S. Benzinger and Y. Wang), P50AG005681 (J.C. Morris), P01AG003991 (J.C. Morris), P01AG026276 (J.C. Morris), the Foundation for Barnes-Jewish Hospital (J.C. Morris), and the Cure Alzheimers Fund (K.L. Moulder). L. Piccio was supported by a grant from the Fondazione Italiana Sclerosi Multipla (FISM $2017 / \mathrm{R} / 20$ ) and cofinanced with the 5 per mille public funding. For the replication cohort from the Alzheimer's Disease Neuroimaging Initiative $(\mathrm{ADNI})$, data collection and sharing were funded by the ADNI (NIH Grant U01 AG024904) and DOD ADNI (Department of Defense award number W81XWH-12-2-0012). The ADNI is funded by the National Institute on Aging, the National Institute of Biomedical Imaging and Bioengineering, and through generous contributions from the following: AbbVie, Alzheimers Association; Alzheimers Drug Discovery Foundation; Araclon Biotech; BioClinica, Inc.; Biogen; Bristol-Myers Squibb Company; CereSpir, Inc.; Cogstate; Eisai Inc.; Elan Pharmaceuticals, Inc.; Eli Lilly and Company; EuroImmun; F. HoffmannLa Roche Ltd and its affiliated company Genentech, Inc.; Fujirebio; GE Healthcare; IXICO Ltd.; Janssen Alzheimer Immunotherapy Research \& Development, LLC.; Johnson \& Johnson Pharmaceutical Research \& Development LLC.; Lumosity; Lundbeck; Merck \& Co., Inc.; Meso Scale Diagnostics, LLC.; NeuroRx Research; Neurotrack Technologies; Novartis Pharmaceuticals Corporation; Pfizer Inc.; Piramal Imaging; Servier; Takeda Pharmaceutical Company; and Transition Therapeutics. The Canadian Institutes of Health Research is providing funds to support ADNI clinical sites in Canada. Private sector contributions are facilitated by the Foundation for the NIH (fnih.org). The grantee organization is the Northern California Institute for Research and Education, and the study is coordinated by the Alzheimers Therapeutic Research Institute at the University of Southern California. ADNI data are disseminated by the Laboratory for Neuro Imaging at the University of Southern California.

\section{Disclosure}

S.E. Schindler reports no disclosures relevant to the manuscript. C. Cruchaga receives research support from Biogen, EISAI, Alector, and Parabon and is a member of the advisory board of ADx Healthcare, Halia Therapeutics, and Vivid Genomics. A. Joseph, L. McCue, F.H.G. Farias, C.H. Wilkins, Y. Deming, R.L. Henson, and R.J. Mikesell report no disclosures relevant to the manuscript. L. Piccio receives research support from Alector. J.J. Llibre-Guerra and K.L. Moulder report no disclosures relevant to the manuscript. A.M. Fagan has received research funding from Biogen, Fujirebio, and Roche Diagnostics; she is a member of the scientific advisory boards for Roche Diagnostics, Genentech, and AbbVie; and she consults for Araclon/Grifols, DiademRes, DiamiR, and Otsuka Pharmaceuticals. B.M. Ances reports no disclosures relevant to the manuscript. T.L.S. Benzinger has received research support from Avid Radiopharmaceuticals (a wholly owned subsidiary of Eli Lilly) and Biogen; she has or is currently participating in clinical trials sponsored by Janssen, Eli Lilly, Pfizer, Biogen, and Roche; and she has received travel support from Biogen, the American Society for Neuroradiology, the Alzheimer's Association, and the People's Republic of China. C. Xiong reports no disclosures relevant to the manuscript. D.M. Holtzman cofounded and is on the scientific advisory board of C2N Diagnostics. Washington University and D.M. Holtzman have equity ownership interest in $\mathrm{C} 2 \mathrm{~N}$ Diagnostics and receive royalty income based on technology (stable isotope labeling kinetics and blood plasma assay) licensed by Washington University to C2N Diagnostics; he receives income from C2N Diagnostics for serving on the scientific advisory board; he is on the scientific advisory board of Denali and Genentech and consults for Merck and Idorsia; his laboratory receives research support from C2N Diagnostics and NextCure. J.C. Morris is the Chair of the Research Strategy Council of the Cure Alzheimer's Fund. Go to Neurology.org/NG for full disclosures.

\section{Publication History}

Received by Neurology: Genetics October 22, 2020. Accepted in final form January 20, 2021.

Appendix Authors

\begin{tabular}{|c|c|c|}
\hline Name & Location & Contribution \\
\hline $\begin{array}{l}\text { Suzanne E. } \\
\text { Schindler, } \\
\text { MD, PhD }\end{array}$ & $\begin{array}{l}\text { Washington University, } \\
\text { St. Louis, MO }\end{array}$ & $\begin{array}{l}\text { Drafting/revision of the } \\
\text { manuscript for content, } \\
\text { including medical writing for } \\
\text { content; major role in the } \\
\text { acquisition of data; study } \\
\text { concept or design; and } \\
\text { analysis or interpretation of } \\
\text { data }\end{array}$ \\
\hline
\end{tabular}


Appendix (continued)

\begin{tabular}{lll}
\hline Name & Location & Contribution \\
\hline $\begin{array}{l}\text { Carlos } \\
\text { Cruchaga, }\end{array}$ & Washington University, & Drafting/revision of the \\
PhD & St. Louis, MO & $\begin{array}{l}\text { manuscript for content, } \\
\text { including medical writing for } \\
\text { content; major role in the } \\
\text { acquisition of data; and } \\
\text { analysis or interpretation of } \\
\text { data }\end{array}$ \\
\hline
\end{tabular}

\begin{tabular}{ll}
\hline Amulya & Washington University, \\
Joseph, BA & St. Louis, MO
\end{tabular}

Drafting/revision of the manuscript for content, including medical writing for content, and analysis or interpretation of data

\begin{tabular}{lll}
\hline Lena McCue, & $\begin{array}{l}\text { Washington University, } \\
\text { PhD }\end{array}$ & $\begin{array}{l}\text { Drafting/revision of the } \\
\text { manuscript for content, } \\
\text { including medical writing for } \\
\text { content; analysis or } \\
\text { interpretation of data; and } \\
\text { statistical analysis }\end{array}$
\end{tabular}

Fabiana H.G. Washington University, Drafting/revision of the Farias, PhD St. Louis, MO manuscript for content, including medical writing for content; major role in the acquisition of data; and analysis or interpretation of data

\begin{tabular}{ll}
\hline Consuelo H. & Vanderbilt University and \\
Wilkins, MD, & Meharry Medical College, \\
MSci & Nashville, TN
\end{tabular}

Drafting/revision of the manuscript for content, including medical writing for content, and analysis or interpretation of data

\begin{tabular}{lll}
\hline $\begin{array}{l}\text { Yuetiva } \\
\text { Deming, } \\
\text { PhD }\end{array}$ & $\begin{array}{l}\text { University of Wisconsin, } \\
\text { Madison }\end{array}$ & $\begin{array}{l}\text { Drafting/revision of the } \\
\text { manuscript for content, } \\
\text { including medical writing for } \\
\text { content, and analysis or } \\
\text { interpretation of data }\end{array}$ \\
\hline $\begin{array}{l}\text { Rachel L. } \\
\text { Henson, MS }\end{array}$ & $\begin{array}{l}\text { Washington University, } \\
\text { St. Louis, MO }\end{array}$ & $\begin{array}{l}\text { Drafting/revision of the } \\
\text { manuscript for content, } \\
\text { including medical writing for } \\
\text { content; major role in the } \\
\text { acquisition of data; and } \\
\text { analysis or interpretation of } \\
\text { data }\end{array}$ \\
\hline
\end{tabular}

\begin{tabular}{ll}
\hline Robert J. & Washington University, \\
Mikesell, BS & St. Louis, MO
\end{tabular}

Drafting/revision of the manuscript for content, including medical writing for content, and major role in the acquisition of data

\begin{tabular}{ll}
\hline Laura Piccio, & University of Sydney, \\
MD, PhD & Australia
\end{tabular}

Drafting/revision of the manuscript for content, including medical writing for content; major role in the acquisition of data; and analysis or interpretation of data

\begin{tabular}{|c|c|c|}
\hline $\begin{array}{l}\text { Jorge J. } \\
\text { Llibre- } \\
\text { Guerra, MD, } \\
\text { MSc }\end{array}$ & $\begin{array}{l}\text { Washington University, } \\
\text { St. Louis, MO }\end{array}$ & $\begin{array}{l}\text { Drafting/revision of the } \\
\text { manuscript for content, } \\
\text { including medical writing for } \\
\text { content, and analysis or } \\
\text { interpretation of data }\end{array}$ \\
\hline $\begin{array}{l}\text { Krista L. } \\
\text { Moulder, } \\
\text { PhD }\end{array}$ & $\begin{array}{l}\text { Washington University, } \\
\text { St. Louis, MO }\end{array}$ & $\begin{array}{l}\text { Drafting/revision of the } \\
\text { manuscript for content, } \\
\text { including medical writing for } \\
\text { content, and analysis or } \\
\text { interpretation of data }\end{array}$ \\
\hline
\end{tabular}

Appendix (continued)

\begin{tabular}{lll}
\hline Name & Location & Contribution \\
\hline $\begin{array}{l}\text { Anne M. } \\
\text { Fagan, PhD }\end{array}$ & Washington University, & $\begin{array}{l}\text { Drafting/revision of the } \\
\text { manuscript for content, } \\
\text { including medical writing for } \\
\text { content; major role in the } \\
\text { acquisition of data; and } \\
\text { analysis or interpretation of } \\
\text { data }\end{array}$ \\
& &
\end{tabular}

\begin{tabular}{lll}
\hline $\begin{array}{l}\text { Beau M. } \\
\text { Ances, MD, } \\
\text { PhD }\end{array}$ & $\begin{array}{l}\text { Washington University, } \\
\text { St. Louis, MO }\end{array}$ & $\begin{array}{l}\text { Drafting/revision of the } \\
\text { manuscript for content, } \\
\text { including medical writing for } \\
\text { content, and analysis or } \\
\text { interpretation of data }\end{array}$ \\
\hline $\begin{array}{l}\text { Tammie L.S. } \\
\text { Benzinger, } \\
\text { MD, PhD }\end{array}$ & $\begin{array}{l}\text { Washington University, } \\
\text { St. Louis, MO }\end{array}$ & $\begin{array}{l}\text { Drafting/revision of the } \\
\text { manuscript for content, } \\
\text { including medical writing for } \\
\text { content, and analysis or } \\
\text { interpretation of data }\end{array}$ \\
\hline $\begin{array}{lll}\text { Chengjie } \\
\text { Xiong, PhD }\end{array}$ & Washington University, & $\begin{array}{l}\text { Drafting/revision of the } \\
\text { manuscript for content, } \\
\text { including medical writing for } \\
\text { content; study concept or } \\
\text { design; analysis or } \\
\text { interpretation of data; and } \\
\text { statistical analysis }\end{array}$ \\
& & Souis, MO \\
\hline
\end{tabular}

\begin{tabular}{lll}
\hline $\begin{array}{l}\text { David M. } \\
\text { Holtzman, } \\
\text { MD }\end{array}$ & $\begin{array}{l}\text { Washington University, } \\
\text { St. Louis, MO }\end{array}$ & $\begin{array}{l}\text { Drafting/revision of the } \\
\text { manuscript for content, } \\
\text { including medical writing for } \\
\text { content, and analysis or } \\
\text { interpretation of data }\end{array}$ \\
\hline $\begin{array}{l}\text { John C. } \\
\text { Morris, MD }\end{array}$ & $\begin{array}{l}\text { Washington University, } \\
\text { St. Louis, MO }\end{array}$ & $\begin{array}{l}\text { Drafting/revision of the } \\
\text { manuscript for content, } \\
\text { including medical writing for } \\
\text { content; major role in the } \\
\text { acquisition of data; study } \\
\text { concept or design; and } \\
\text { analysis or interpretation of } \\
\text { data }\end{array}$ \\
\hline
\end{tabular}

\section{References}

1. Babulal GM, Quiroz YT, Albensi BC, et al. Perspectives on ethnic and racial disparities in Alzheimer's disease and related dementias: update and areas of immediate need. Alzheimers Dement 2019;15:292-312.

2. Howell JC, Watts KD, Parker MW, et al. Race modifies the relationship between cognition and Alzheimer's disease cerebrospinal fluid biomarkers. Alzheimers Res Ther 2017;9:88.

3. Gottesman RF, Schneider AL, Zhou Y, et al. The ARIC-PET amyloid imaging study: brain amyloid differences by age, race, sex, and APOE. Neurology 2016;87:473-480.

4. Morris JC, Schindler SE, McCue LM, et al. Assessment of racial disparities in biomarkers for Alzheimer disease. JAMA Neurol 2019;76:264-273.

5. Garrett SL, McDaniel D, Obideen M, et al. Racial disparity in cerebrospinal fluid amyloid and tau biomarkers and associated cutoffs for mild cognitive impairment. JAMA Netw Open 2019;2:e1917363.

6. Bonham VL, Green ED, Perez-Stable EJ. Examining how race, ethnicity, and ancestry data are used in biomedical research. JAMA 2018;320:1533-1534.

7. Yaffe K, Falvey C, Harris TB, et al. Effect of socioeconomic disparities on incidence of dementia among biracial older adults: prospective study. BMJ 2013;347:f7051.

8. Gross AL, Mungas DM, Crane PK, et al. Effects of education and race on cognitive decline: an integrative study of generalizability versus study-specific results. Psychol Aging 2015;30:863-880.

9. Gilsanz P, Quesenberry CP Jr, Mayeda ER, Glymour MM, Farias ST, Whitmer RA. Stressors in midlife and risk of dementia: the role of race and education. Alzheimer Dis Assoc Disord 2019;33:200-205.

10. Reitz C, Jun G, Naj A, et al. Variants in the ATP-binding cassette transporter (ABCA7), apolipoprotein E 4,and the risk of late-onset Alzheimer disease in African Americans. JAMA 2013;309:1483-1492.

11. Wang Y, Cella M, Mallinson K, et al. TREM2 lipid sensing sustains the microglial response in an Alzheimer's disease model. Cell 2015;160:1061-1071.

12. Zhao $\mathrm{Y}, \mathrm{Wu} \mathrm{X}, \mathrm{Li} \mathrm{X}$, et al. TREM2 is a receptor for beta-amyloid that mediates microglial function. Neuron 2018;97:1023-1031.e7. 
13. Guerreiro R, Wojtas A, Bras J, et al. TREM2 variants in Alzheimer's disease. N Engl J Med 2013;368:117-127.

14. Jonsson T, Stefansson H, Steinberg S, et al. Variant of TREM2 associated with the risk of Alzheimer's disease. N Engl J Med 2013;368:107-116.

15. Jin SC, Benitez BA, Karch CM, et al. Coding variants in TREM2 increase risk for Alzheimer's disease. Hum Mol Genet 2014;23:5838-5846.

16. Ulrich JD, Holtzman DM. TREM2 function in Alzheimer's disease and neurodegeneration. ACS Chem Neurosci 2016;7:420-427.

17. Jin SC, Carrasquillo MM, Benitez BA, et al. TREM2 is associated with increased risk for Alzheimer's disease in African Americans. Mol Neurodegener 2015;10:19.

18. Del-Aguila JL, Benitez BA, Li Z, et al. TREM2 brain transcript-specific studies in AD and TREM2 mutation carriers. Mol Neurodegener 2019;14:18

19. Kleinberger G, Yamanishi Y, Suarez-Calvet M, et al. TREM2 mutations implicated in neurodegeneration impair cell surface transport and phagocytosis. Sci Transl Med 2014;6:243ra286

20. Ewers M, Franzmeier N, Suarez-Calvet M, et al. Increased soluble TREM2 in cerebrospinal fluid is associated with reduced cognitive and clinical decline in Alzheimer's disease. Sci Transl Med 2019;11:eaav6221.

21. Piccio L, Deming Y, Del-Aguila JL, et al. Cerebrospinal fluid soluble TREM2 is higher in Alzheimer disease and associated with mutation status. Acta Neuropathol 2016; 131:925-933.

22. Deming Y, Filipello F, Cignarella F, et al. The MS4A gene cluster is a key modulator of soluble TREM2 and Alzheimer's disease risk. Sci Transl Med 2019;11:eaau2291.

23. Lambert JC, Ibrahim-Verbaas CA, Harold D, et al. Meta-analysis of 74,046 individuals identifies 11 new susceptibility loci for Alzheimer's disease. Nat Genet 2013;45: 1452-1458.

24. Morris JC, Weintraub S, Chui HC, et al. The Uniform Data Set (UDS): clinical and cognitive variables and descriptive data from Alzheimer Disease Centers. Alzheimer Dis Assoc Disord 2006;20:210-216.

25. Morris JC. The Clinical Dementia Rating (CDR): current version and scoring rules. Neurology 1993;43:2412-2414.

26. Folstein MF, Folstein SE, McHugh PR. "Mini-mental state”. A practical method for grading the cognitive state of patients for the clinician. J Psychiatr Res 1975;12: 189-198.

27. Cruchaga C, Kauwe JS, Mayo K, et al. SNPs associated with cerebrospinal fluid phospho-tau levels influence rate of decline in Alzheimer's disease. PLoS Genet 2010; 6:e1001101.

28. Chang CC, Chow CC, Tellier LC, Vattikuti S, Purcell SM, Lee JJ. Second-generation PLINK: rising to the challenge of larger and richer datasets. Gigascience 2015;4:7.

29. Pemberton TJ, Wang $\mathrm{C}, \mathrm{Li}$ JZ, Rosenberg NA. Inference of unexpected genetic relatedness among individuals in HapMap Phase III. Am J Hum Genet 2010;87: 457-464.

30. Schindler SE, Gray JD, Gordon BA, et al. Cerebrospinal fluid biomarkers measured by Elecsys assays compared to amyloid imaging. Alzheimers Dement 2018;14: 1460-1469.
31. Wilkins $\mathrm{CH}$, Schindler SE, Morris JC. Addressing health disparities among minority populations: why clinical trial recruitment is not enough. JAMA Neurol 2020;77: 1063-1064.

32. Lee CYD, Daggett A, Gu X, et al. Elevated TREM2 gene dosage reprograms microglia responsivity and ameliorates pathological phenotypes in Alzheimer's disease models. Neuron 2018;97:1032-1048.e5.

33. Wang Y, Ulland TK, Ulrich JD, et al. TREM2-mediated early microglial response limits diffusion and toxicity of amyloid plaques. J Exp Med 2016;213:667-675.

34. Yuan P, Condello C, Keene CD, et al. TREM2 haplodeficiency in mice and humans impairs the microglia barrier function leading to decreased amyloid compaction and severe axonal dystrophy. Neuron 2016;92:252-264.

35. Leyns CEG, Gratuze M, Narasimhan S, et al. TREM2 function impedes tau seeding in neuritic plaques. Nat Neurosci 2019;22:1217-1222.

36. Suarez-Calvet M, Kleinberger G, Araque Caballero MA, et al. sTREM2 cerebrospinal fluid levels are a potential biomarker for microglia activity in early-stage Alzheimer's disease and associate with neuronal injury markers. EMBO Mol Med 2016;8:466-476.

37. Cummings J, Lee G, Ritter A, Sabbagh M, Zhong K. Alzheimer's disease drug development pipeline: 2019. Alzheimers Dement 2019;5:272-293.

38. Xiang X, Werner G, Bohrmann B, et al. TREM2 deficiency reduces the efficacy of immunotherapeutic amyloid clearance. EMBO Mol Med 2016;8:992-1004.

39. Honig LS, Vellas B, Woodward M, et al. Trial of solanezumab for mild dementia due to Alzheimer's disease. N Engl J Med 2018;378:321-330.

40. Egan MF, Kost J, Tariot PN, et al. Randomized trial of verubecestat for mild-tomoderate Alzheimer's disease. N Engl J Med 2018;378:1691-1703.

41. Kober DL, Brett TJ. TREM2-ligand interactions in health and disease. J Mol Biol 2017;429:1607-1629.

42. Steenland K, Goldstein FC, Levey A, Wharton W. A meta-analysis of Alzheimer's disease incidence and prevalence comparing African-Americans and Caucasians. J Alzheimers Dis 2016;50:71-76.

43. Mayeda ER, Glymour MM, Quesenberry CP, Whitmer RA. Inequalities in dementia incidence between six racial and ethnic groups over 14 years. Alzheimers Dement 2016;12:216-224

44. Xiong C, Luo J, Coble D, Agboola F, Kukull W, Morris JC. Complex interactions underlie racial disparity in the risk of developing Alzheimer's disease dementia. Alzheimers Dement 2020;16:589-597.

45. Bridel C, van Wieringen WN, Zetterberg H, et al. Diagnostic value of cerebrospinal fluid neurofilament light protein in neurology: a systematic review and meta-analysis. JAMA Neurol 2019;76:1035-1048.

46. George S, Duran N, Norris K. A systematic review of barriers and facilitators to minority research participation among African Americans, Latinos, Asian Americans, and Pacific Islanders. Am J Public Health 2014;104:e16-e31.

47. Pernick MS. Eugenics and public health in American history. Am J Public Health 1997;87:1767-1772.

48. Wu J, Kraja AT, Oberman A, et al. A summary of the effects of antihypertensive medications on measured blood pressure. Am J Hypertens 2005; 18:935-942. 


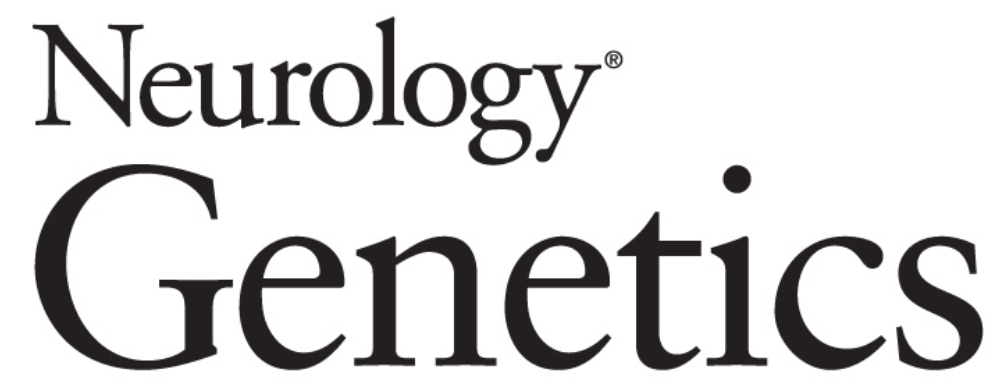

African Americans Have Differences in CSF Soluble TREM2 and Associated Genetic Variants

Suzanne E. Schindler, Carlos Cruchaga, Amulya Joseph, et al. Neurol Genet 2021;7;

DOI 10.1212/NXG.0000000000000571

This information is current as of March 4, 2021

Neurol Genet is an official journal of the American Academy of Neurology. Published since April 2015, it is an open-access, online-only, continuous publication journal. Copyright Copyright $(2021$ The Author(s). Published by Wolters Kluwer Health, Inc. on behalf of the American Academy of Neurology.. All rights reserved. Online ISSN: 2376-7839.

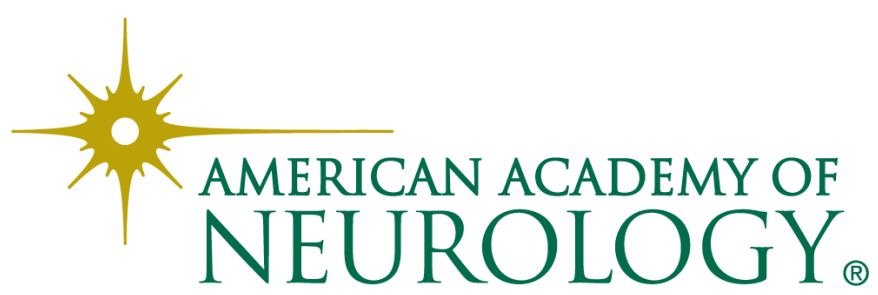




\section{Updated Information \& Services}

References

Citations

Subspecialty Collections

\section{Errata}

Permissions \& Licensing

Reprints including high resolution figures, can be found at: http://ng.neurology.org/content/7/2/e571.full.html

This article cites 48 articles, 6 of which you can access for free at: http://ng.neurology.org/content/7/2/e571.full.html\#\#ref-list-1

This article has been cited by 2 HighWire-hosted articles: http://ng.neurology.org/content/7/2/e571.full.html\#\#otherarticles

This article, along with others on similar topics, appears in the following collection(s):

All Immunology

http://ng.neurology.org//cgi/collection/all_immunology

Alzheimer's disease

http://ng.neurology.org//cgi/collection/alzheimers_disease

Association studies in genetics

http://ng.neurology.org//cgi/collection/association_studies_in_genetics Health disparities

http://ng.neurology.org//cgi/collection/health_disparities

An erratum has been published regarding this article. Please see next page or:

/content/7/3/e594.full.pdf

Information about reproducing this article in parts (figures,tables) or in its entirety can be found online at:

http://ng.neurology.org/misc/about.xhtml\#permissions

Information about ordering reprints can be found online: http://ng.neurology.org/misc/addir.xhtml\#reprintsus

Neurol Genet is an official journal of the American Academy of Neurology. Published since April 2015, it is an open-access, online-only, continuous publication journal. Copyright Copyright $\odot 2021$ The Author(s). Published by Wolters Kluwer Health, Inc. on behalf of the American Academy of Neurology.. All rights reserved. Online ISSN: 2376-7839.

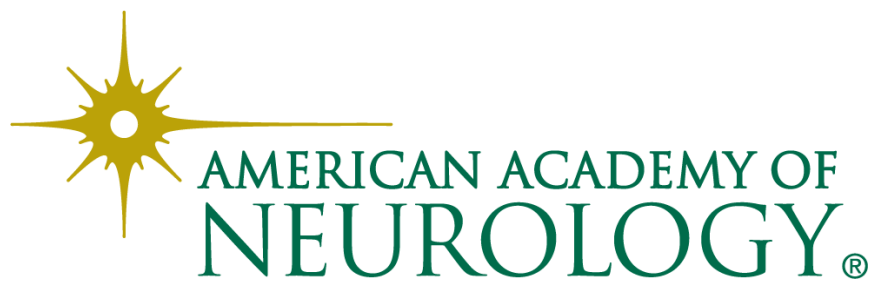




\section{African Americans Have Differences in CSF Soluble TREM2 and Associated Genetic Variants}

Neurol Genet 2021;7:e594. doi:10.1212/NXG.0000000000000594

In the article "African Americans Have Differences in CSF Soluble TREM2 and Associated Genetic Variants" by Schindler et al., there were errors in the x-axis of figure 2C. The third label from the left should read, "TREM2 variant noncarrier rs1582763 (A) noncarrier AA ( $n=63)$ "; the fifth label should read, "TREM2 variant carrier rs 1582763 (A) carrier AA ( $\mathrm{n}=1)$ "; the sixth label should read "TREM2 variant carrier rs1582763 (A) carrier NHW ( $=21)$ "; and the eighth label should read, "TREM2 variant noncarrier rs1582763 (A) carrier NHW (n = 492)." The correct figure is published here. The editorial staff regret the errors.
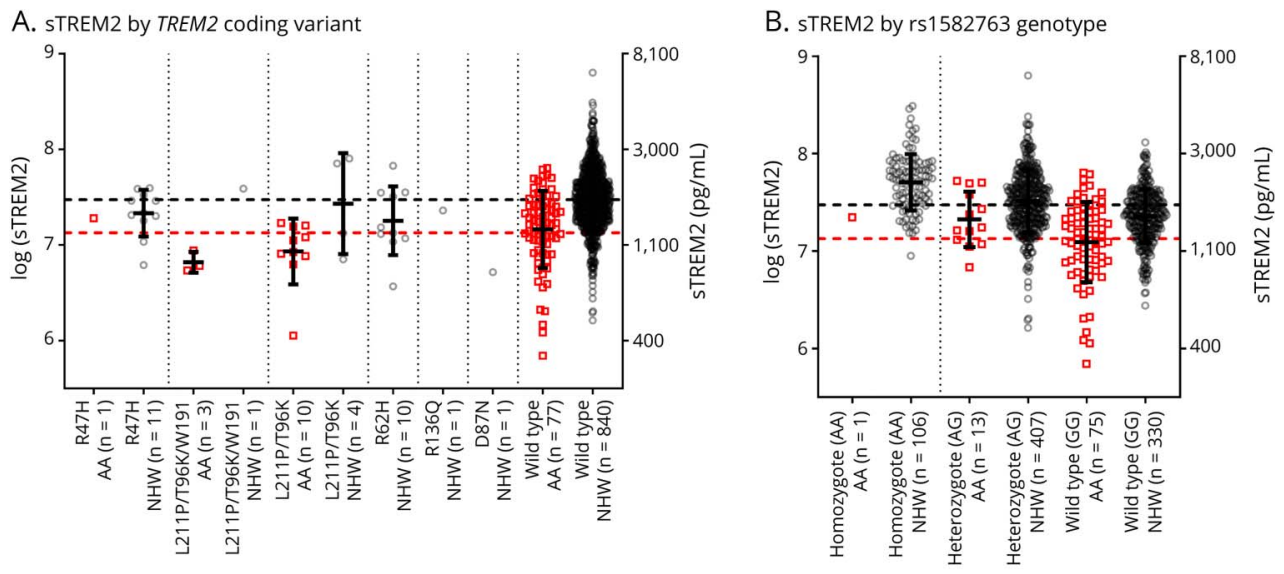

C. STREM 2 by TREM 2 coding variant status and $r s 1582763$ (A) carrier status

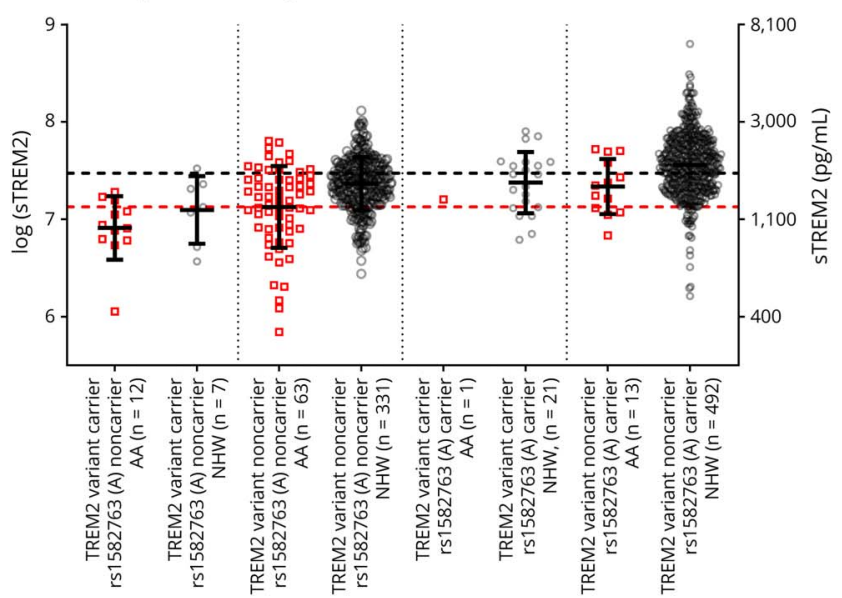

\section{Reference}

1. Schindler SE, Cruchaga C, Joseph A, et al. African Americans have differences in CSF soluble TREM2 and associated genetic variants. Neurol Genet 2021;7:e571. doi: 10.1212/NXG.0000000000000571. 